\title{
The Design of Control Force Measurement Device for Aircraft Quick Evaluation Flight Test
}

\author{
Zhang Dawei, Chen Mingtai \\ Shanghai Aircraft Design and Research Institute \\ zhangdawei@comac.cc
}

\author{
Mi Yi, Liu Chaoqiang \\ Shanghai Aircraft Design and Research Institute \\ zhangdawei@comac.cc
}

\section{SPRING BALANCE}

Spring balance was used as a control force indication device to measure the wheel force and stick force. The advantage of the spring balance is that the extension of the spring is approximately proportional to the force applied. Also, almost no modification or installation device was needed to measure force using spring balance. The device can be used on most control columns without modification.

\section{A. Theory}

Hooke's law states that the extension of a spring is in direct proportion with the load applied to it, which is usually known as: $\mathrm{F}=\mathrm{k} \triangle \mathrm{x}$. The spring balance is based on this principle.

\section{B. Application}

The installation of the spring balance was simple. Nylon bandage was tied on the wheel or stick. The rope must be loose. During the test, the spring balance was hooked on the rope at one side of the spring balance. The pilot controlled the aircraft with the other side of the spring balance.

The spring balance was tested on Jabiru and Baron E55. Longitudinal and lateral-directional static stability of Jabiru and Baron E55 were evaluated. It was shown in Fig. 1. The force range of the spring balance used in Jabiru static stability test was 0 to $10 \mathrm{~kg}$. The resolution of the spring balance was $0.25 \mathrm{~kg}$.

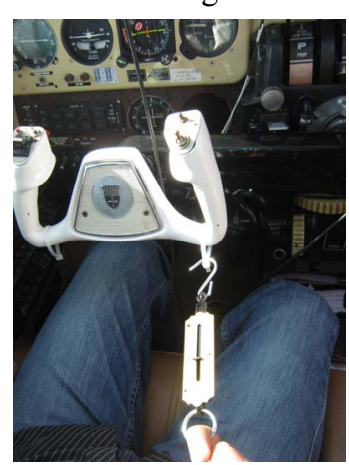

1a. Longitudinal test

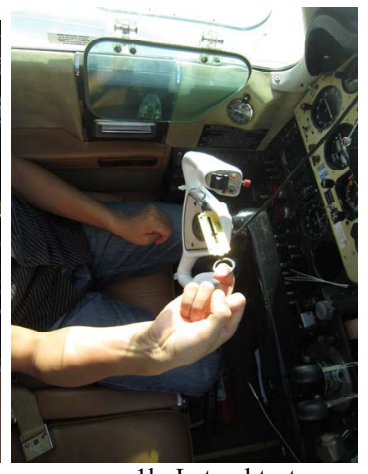

1b. Lateral test
Figure 1. Spring balance used in Baron E55 static stability test

\section{Results and Conclusions}

Some of Jabiru and Baron E55 longitudinal and lateral static stability results are shown in Fig. 2. 


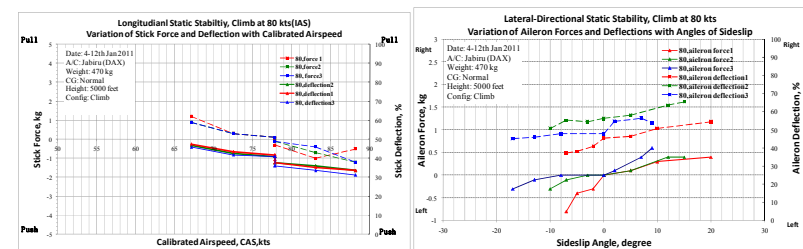

2a Longitudinal and lateral-directional static stability test results of Jabiru

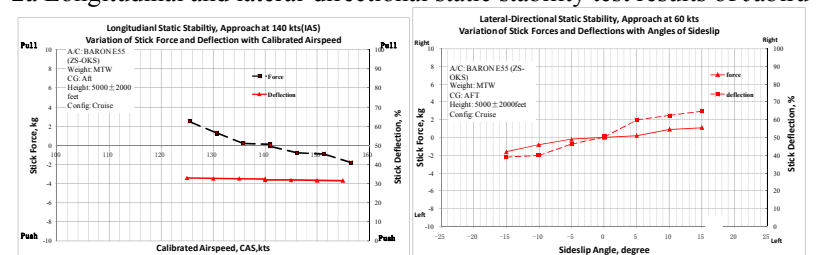

2a Longitudinal and lateral-directional static stability test results of Baron E55

Figure 2. control force measured by spring balance

The test results show that spring balance can be used to measure control force of Jabiru and Baron E55. However, certain scatter existed due to the resolution of the spring balance which was $0.25 \mathrm{~kg}$. It was not satisfactory. It is recommended that a spring balance which resolution is 0.1 $\mathrm{kg}$ should be used.

The disadvantage of using the spring balance to measure the stick/ wheel force is that the pilot must pull the spring to control the aircraft, it was not normal. The pilot workload is increased. It could influence the quality opinion of the pilot on the handling quality of the aircraft. Certain error could be introduced due to the control position change of using spring balance.

During the test, the position where the spring balance hooked on the stick and wheel was not fixed. Certain error might be introduced due to the arm change. It was not satisfactory. It is recommended that certain installation device should be added to keep the arm constant. Control Force Indication Glove

The control force range varies with different kinds of aircraft. For some aircraft, the stick force never exceeds $5 \mathrm{~kg}$. However, for some aircraft, the stick force can go up to more than $20 \mathrm{~kg}$. Different kinds of control columns need different kinds of installation devices. Even for same type of control columns, the installation devices could be totally different.

It would cost a long time to design, manufacture and install the control force device. For a new designed aircraft, this problem is not severe. However, only a short time preparation is available for quick evaluation flight test and for a verification flight test after modification or equipment upgrade. For this kind of flight test, PnP control force indication device is needed. A universal control indication device is needed.

Conventionally, the load sensors were packaged up and fixed onto the control column directly. Instead of the conventional direct measurement method, an indirect measurement method was proposed.

\section{Theory}

The load sensors were fixed onto a glove. With this glove, the sensor installation device was not necessary any more. The pilot just needs to put on the glove and goes on with the test.

An electronic weight scale was modified and reassembled to measure the force. The electronic weight scale was comprised of load sensors, operational amplifier, A/D convertor, SCM and LCD display. The schematic diagram of the weight scale is shown in Fig. 3.

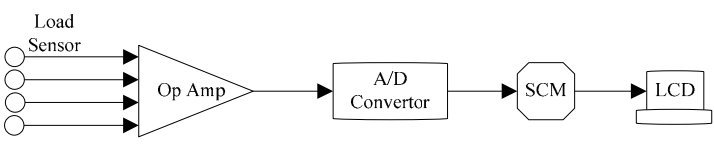

Figure 3. Schematic Diagram of the Weight Scale

\section{E. Application}

Four load sensors were took out from weight scale and fixed onto the glove. The switch which was originally installed below the sensor had been relocated to near the display for easy handling.

Fastening tape was used to fix the sensor onto the glove. One side of the fastening tape was sewn on to the glove, while the sensor was sewn onto the other side of the fastening tape. Therefore, the position of the sensor could be conveniently changed.

Four sensors were fixed onto the glove. Two sensors were located onto the palm of the glove in a line. They were used to push the control column. The other two sensors were located onto the figures of the glove. They were used to pull the aircraft easier. During the test, one sensor or several sensors could be used together. The summation of the force added on four sensors was shown on the display. Therefore, the glove could be used to almost all kinds of aircraft. It was shown in Fig. 4.

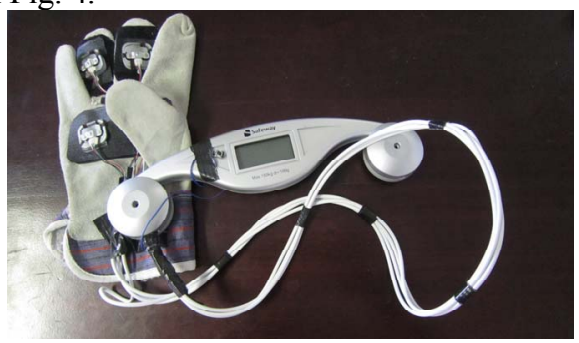

Figure 4. Control Force Indication Glove

The glove was tested on Jabiru and Baron E55. Longitudinal and lateral-directional static stability of Jabiru and Baron E-55 were evaluated.

\section{F. Results and Conclusions}

No installation work was needed on application of control force indication glove on Jabiru and Baron E-55. A side stick was equipped on Jabiru to control the pitch and roll. The test showed that it was very convenient to measure the stick force of Jabiru using the control force indication glove and the control force indication glove could be used to 
measure the longitudinal and lateral control force of Jabiru stick directly. Two wheels were equipped on BARON E-55. One was for the pilot and the other was for the co-pilot. The test showed that it was very convenient to measure the stick force of Baron E55 using the control force indication glove and the control force indication.

The control force indication glove could be used to measure the longitudinal and lateral control force of Jabiru stick and Baron E55 yoke directly. However, the resolution of the control force indication glove was $0.1 \mathrm{~kg}$ and it ranged from $2 \mathrm{~kg}$ to $100 \mathrm{~kg}$. Most of the stick force of Jabiru and wheel force of Baron E55 measured during longitudinal and lateral-directional flight test was less than $2 \mathrm{~kg}$. The control force indication glove failed to measure the forces when the forces were less than $2 \mathrm{~kg}$. It was unacceptable. The range of the control force indication glove must be changed in order to measure the force less than $2 \mathrm{~kg}$. Other load sensor must be used.

\section{FLEXIFORCE INDICATOR}

As the maturity of integrated circuit technology and the rapid development of liquid crystal display, most of the control force measurement was conducted using pressure sensor circuit. There were various kinds of pressure sensors available. Resistance sensitive pressure sensors and capacitance sensitive pressure sensors were used most widely.

Flexiforce sensor which was manufactured by an U.S company called Tekscan ${ }^{\circledR}$ was to provide simple and effective real time control force indication. Based on the FlexiForce sensor, a circuit was designed and assembled. Installation device and calibration device was also designed and assembled.

\section{A. Flexiforce Sensor}

Flexiforce sensor was made of pressure sensitive material. The resistance of the sensor decreased with pressure nonlinearly. However, with proper design, approximately linear voltage signal could be produced, which was an indication of the pressure.

\section{B. The circuit of the FlexiForce indicator}

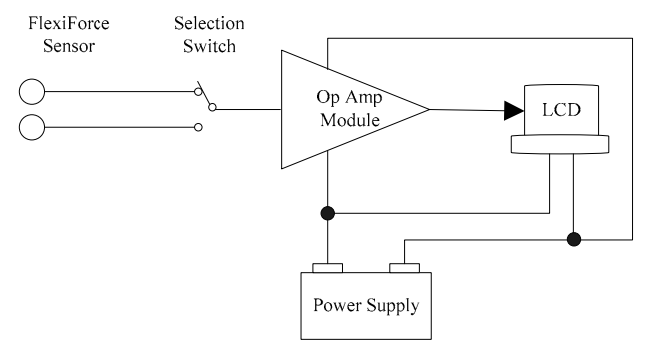

Figure 5. Schematic diagram of the circuit of the FlexiForce indicator

The schematic diagram of the circuit is shown in Fig. 5. Two FlexiForce sensors were connected to a selection switch. The function of the switch was to control the on-off of the two sensors. The sensor was connected to the operational amplifier module and the output of the amplifier module was exported to the LCD. SCM and A/D convertor was assembled into the LCD

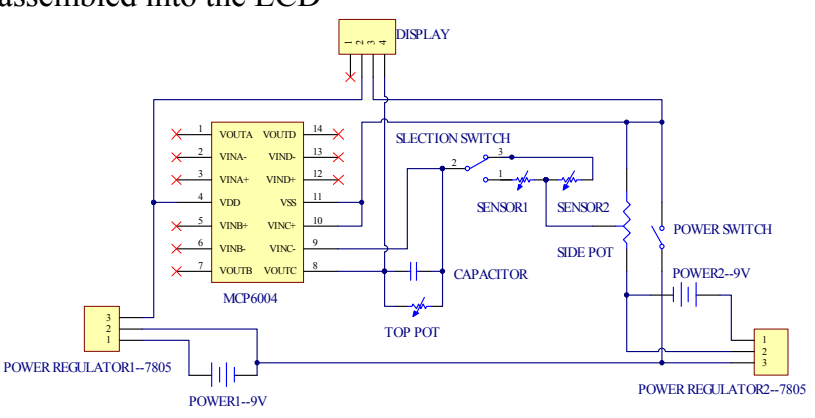

Figure 6. FlexiForce Indicator Circuit

The FlexiForce indicator circuit was shown in Fig. 6. It was a dual source circuit, which was comprised of one operational amplifier chip MCP 6004, two variable resistances, two regulators, two batteries, one capacitor, two switches and one display.

\section{Application}

All the components were sealed onto a multi-hole board and container was designed to hold the board.

The FlexiForce indicator was installed on Baron E55 and the Vmca and Vmcl was tested. The test was conducted at around 5,000 feet. The Vmca and Vmcl at different weight and different C.G. were covered. FlexiForce indicator was used to indicate the maximum force used during the recovery of the aircraft from single engine failure. FAR 25.149(d) requires that the pedal force used to control the aircraft after single engine failure must not exceed $150 \mathrm{lbs}$.

\section{Results and Conclusions}

The maximum pedal force of Baron E55 during Vmca and Vmcl was tested. The test result shows that the FelxiForce indication device could be used to measure the pedal force. The Maximum pedal forces of Baron E55 during Vmca and Vmcl determination test were always less than 150 lbs. It met the FAR requirements. With some improvement, the FlexiForce indication device can also be used to measure the stick force and wheel force.

However, the reliability of the FlexiForce indicator was unsatisfactory. The joint of the circuit was easy to disconnect due to the turbulent air and the vibration of the aircraft. PCB should be used to improve the reliability. Also, the installation device was not universal. Specific installation device still need to be designed in order to use the FlexiForce indication device on the other aircraft.

\section{CONCLUSION}

Three control force indication devices were assembled and tested:

Spring balance could be used for quick control force measurement. The disadvantage of spring balance was that it changed the way how the pilot normally controls the aircraft.

The principle of control force indication glove was innovative and it could be used to measure control force 
without modification or installation device. However, the load sensor must be improved.

The FelxiForce indication device could be used to measure the pedal force. With some improvement, the FlexiForce indication device can also be used to measure the stick force and wheel force.

\section{REFERENCES}

[1] Federal Aviation Administration, 14 CFR Part 25-Airworthiness Standards: Transport Category Airplanes.

[2] Federal Aviation Regulations, Part 23 Airworthiness Standards: Normal, Utility, Acrobatic and Commuter Category Airplanes. 